\title{
Letter to the Editor: Backbone resonance assignment of the homodimeric, 35 kDa chaperone CesT from enteropathogenic Escherichia coli
}

\author{
Sigrun Rumpel, Hai-Young Kim, Vinesh Vijayan, Stefan Becker \& \\ Markus Zweckstetter* \\ Department for NMR-based Structural Biology, Max Planck Institute for Biophysical Chemistry, Am \\ Fassberg 11, 37077, Göttingen, Germany
}

Received 24 December 2004; Accepted 27 January 2005

Key words: chaperone, MARS, NMR assignment, type III secretion system

\section{Biological context}

Enteropathogenic Escherichia coli (EPEC) is a human pathogen causing diarrhoea (Nataro and Kaper, 1998). As many Gram-negative bacterial pathogens, it uses a type III secretion system (TTSS) to deliver virulence effector proteins into the eukaryotic cell. Many TTSS effectors have a specific chaperone which is required for secretion. The TTSS chaperones share only limited sequence similarity, tend to form homodimers, are highly acidic and are predicted to contain a C-terminal amphipathic $\alpha$-helix (Wattiau et al., 1996) . Their function is not clearly understood and seems to be versatile. Best known is their role in preventing aggregation or degradation of effector molecules. There is also evidence indicating a regulatory role in the release of effectors (Isberg and Duménil, 2001). The TTSS chaperone CesT is known to be specific for the translocated intimin receptor (Tir) and the mitochondrial associated protein (Map) (Creasey et al., 2003). The crystal structure of CesT with $2.8 \AA$ resolution reveals a domain-swapped homodimer. As all other solved crystal structures of TTSS chaperones do not show a domain swap, the question arises whether it is a crystallographic artefact or facilitates the chaperone-effector interaction (Luo et al., 2001). The backbone assignment of the $35.4 \mathrm{kDa}$ homodimer CesT is a fundamental step to address this question by NMR

\footnotetext{
*To whom correspondence should be addressed. E-mail: mzwecks@gwdg.de
}

and to further understand the mechanism of the TTSS machinery. Furthermore it forms the basis for a structural characterization of the CesT/Tir and CesT/Map complexes.

\section{Methods and experiments}

The coding sequence for CesT was kindly provided by the Frankel laboratory, Imperial College, London. The gene was cloned into the $\mathrm{NdeI}$ and BamHI restriction sites of pET16b (Novagen, Madison, USA) in order to produce His-tagged recombinant protein in E. coli BL21(DE3). The protein was purified by affinity chromatography on a $\mathrm{Ni}^{2+}$-NTA resin (Qiagen) and the His-tag was removed by TEV-protease cleavage. The His-tagged protease was removed on $\mathrm{N} \mathrm{Ni}^{2+}$-NTA resin and the protein was further purified by anion exchange chromatography on a HiTrap Q-Sepharose column (Amersham Biosciences). ${ }^{15} \mathrm{~N} /{ }^{13} \mathrm{C},{ }^{2} \mathrm{H}$ $(75 \%) /{ }^{15} \mathrm{~N}$ and ${ }^{2} \mathrm{H}(75 \%) /{ }^{15} \mathrm{~N} /{ }^{13} \mathrm{C}$ labeled protein samples were prepared from cells grown in M9-based minimal medium containing ${ }^{15} \mathrm{NH}_{4} \mathrm{Cl}$ and/or $99 \% \mathrm{D}_{2} \mathrm{O}$ and/or ${ }^{13} \mathrm{C}_{6}$-glucose. NMR samples contained approximately $1 \mathrm{mM}$ CesT in $50 \mathrm{mM}$ potassium phosphate $\mathrm{pH} 6.8,100 \mathrm{mM} \mathrm{NaCl}, 5 \mathrm{mM}$ DTT, $0.5 \mathrm{mM}$ EDTA and $10 \% \mathrm{D}_{2} \mathrm{O}(\mathrm{v} / \mathrm{v})$.

NMR spectra were acquired at $303 \mathrm{~K}$ on Bruker AVANCE 600, 700 and 900 spectrometers, processed using NMRPipe/NMRDraw (Delaglio et al., 1995) and analysed using Sparky 3 (T.D. Goddard and D.G. Kneller, University of California, 


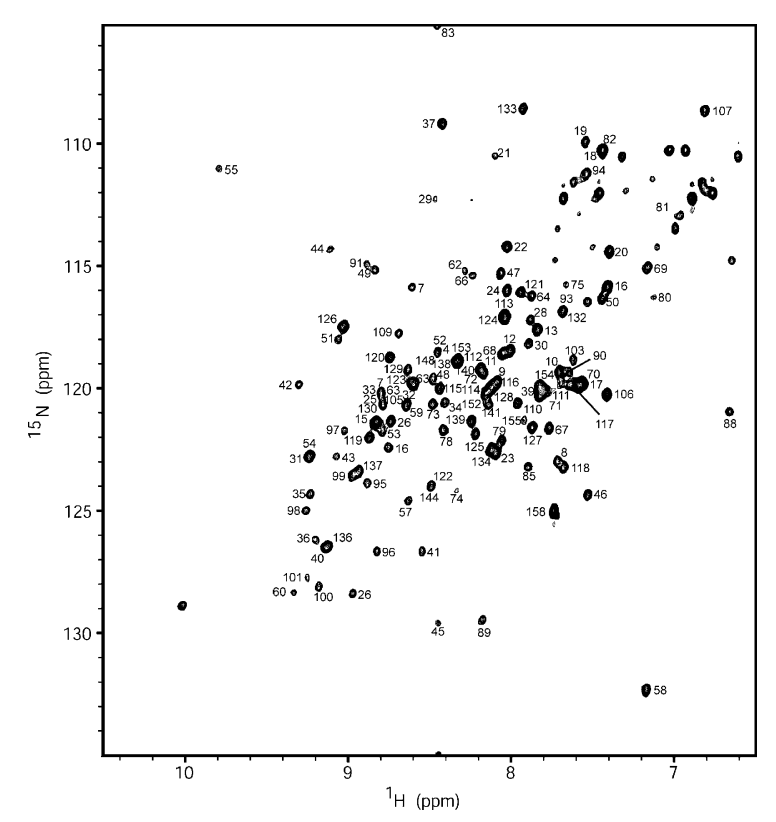

Figure 1. $900 \mathrm{MHz}\left[{ }^{15} \mathrm{~N},{ }^{1} \mathrm{H}\right]-\mathrm{HSQC}$ spectrum of CesT at $303 \mathrm{~K}$. Resonance assignments are indicated with residue numbers. The peak from residue G58 is folded from upfield in $\omega 1$.

San Francisco). Assignments were derived from standard and/or TROSY versions of 3D HNCA, $\mathrm{HN}(\mathrm{CO}) \mathrm{CA}, \mathrm{CBCA}(\mathrm{CO}) \mathrm{NH}, \mathrm{CB}(\mathrm{CACO}) \mathrm{NH}$, $\mathrm{HN}(\mathrm{CA}) \mathrm{CB}, \mathrm{HNCO}$ and $\mathrm{HN}(\mathrm{CA}) \mathrm{CO}$ with deuterium decoupling. A $3 \mathrm{D}\left[{ }^{15} \mathrm{~N},{ }^{1} \mathrm{H}\right]$ NOESYHSQC experiment was used for confirmation of the through-bond data. The assignment was performed in an iterative fashion based on automatic assignment using the program MARS (Jung and Zweckstetter, 2004) and manual assignment within Sparky.

\section{Extent of assignment and data deposition}

Analysis of the triple resonance spectra allowed identification and sequential assignment of $97 \%$ of the backbone amide resonances, not including the ${ }^{15} \mathrm{~N}$ of the five proline residues. Five residues could not be found in the HSQC due to overlap (Figure 1). Of the $\mathrm{C}^{\prime}$ resonances $98.7 \%$, of the $\mathrm{C}^{\alpha}$ resonances $98 \%$ and of the $\mathrm{C}^{\beta}$ resonances $98 \%$ have been assigned unambiguously.

Secondary structure elements were determined from the deviation of the $C^{\alpha}$ and $C^{\beta}$ chemical shifts from the random coil values and by characteristic NOE patterns obtained from the $3 \mathrm{D}\left[{ }^{15} \mathrm{~N},{ }^{1} \mathrm{H}\right]$ NOESY-HSQC. They are consistent with the crystal structure. In the C-terminal part (residues 130-156) no regular secondary structure elements were detected.

The chemical shift data have been deposited in the BioMagResBank (http://www.bmrb.wisc.edu) under accession number 6451 .

\section{Acknowledgements}

This work was supported by the MPG. M.Z. is the recipient of a DFG Emmy Noether-Grant (ZW71/1-4).

\section{References}

Creasey, E.A., Delahay, R.M., Bishop, A.A., Shaw, R.K., Kenny, B., Knutton, S. and Frankel, G. (2003) Mol. Microbiol., 47, 209-221.

Delaglio, F., Grzesiek, S., Vuister, G.W., Zhu, G., Pfeifer, J. and Bax, A. (1995) J. Biomol. NMR, 6, 277-293.

Isberg, R.R. and Duménil, G. (2001) Nat. Struct. Biol., 8, 1006 1008.

Jung, Y.-S. and Zweckstetter, M. (2004) J. Biomol. NMR, 30, $11-23$.

Luo, Y., Bertero, M.G., Frey, E.A., Pfuetzner, R.A., Wenk, M.R., Creagh, L., Marcus, S.L., Lim, D., Sicheri, F., Kay, C., Haynes, C., Finlay, B.B. and Strynadka, N.C.J. (2001) Struct. Biol., 8, 1031-1036.

Nataro, J.P. and Kaper, J.B. (1998) Microbiol. Rev., 11, $142-201$ 